\title{
Snellen Fraction
}

National Cancer Institute

\section{Source}

National Cancer Institute. Snellen Fraction. NCI Thesaurus. Code C87305.

A representation of visual acuity in the form of a fraction that relates a subject's visual acuity to that of a standardized norm. The numerator is the testing distance and the denominator is the relative distance at which a specific line can be read. 